\title{
Matriks Kabur dan Karakteristiknya
}

\author{
Muhammad Abdy ${ }^{1}$, Maya Sari Wahyuni ${ }^{1}$, dan Muh. Hadi Purnomo ${ }^{1, \text { a) }}$ \\ ${ }^{1}$ Jurusan Matematika, Fakultas Matematika dan Ilmu Pengetahuan Alam \\ Universitas Negeri Makassar \\ a)nuzumaki247@gmail.com
}

\begin{abstract}
Abstrak. Penelitian ini mengkaji definisi, operasi, dan teorema pada matriks kabur dan karakteristiknya. Literatur yang digunakan sebagai acuan adalah artikel yang ditulis oleh Pal (2016), Sidky \& Emam (1992), dan Suroto \& Wardayani (2015). Hasilnya dapat diberikan perbaikan pada operasi yang digunakan pada matriks kabur serta teorema himpunan matriks kabur persegi dapat diperluas menjadi teorema himpunan matriks kabur. Selain itu, disimpulkan bahwa himpunan matriks kabur persegi memenuhi sifat aljabar untuk semigrup dan semi ring. Namun tidak memenuhi sifat aljabar untuk grup dan ring.
\end{abstract}

Kata Kunci: Himpunan Kabur, Matriks, Matriks Kabur, Grup, Ring, Semiring.

Abstract. This research examines the definitions, operations, and theorems of fuzzy matrices and their characteristics. The literature used as a reference is an article written by Pal (2016), Sidky \& Emam (1992), and Suroto \& Wardayani (2015). The results can be given improvements to the operations used in the fuzzy matrix and the set of square fuzzy matrix theorems can be extended to fuzzy matrix set theorems. In addition, it was concluded that the set of square fazzy matrix fulfilled the algebraic properties for semigroup and semiring. But it does not fulfill algebraic properties for groups and rings.

Keywords: Fuzzy Set, Matrix, Fuzzy Matrix, Group, Ring, Semiring.

\section{PENDAHULUAN}

Konsep himpunan kabur pertama kali diperkenalkan oleh Zadeh (1965). Teori himpunan kabur tersebut kemudian dikembangkan oleh Thomason (1977) ke dalam teori matriks kabur (fuzzy matrix). Matriks kabur merupakan satu diantara beberapa jenis matriks. Matriks kabur berisi entrientri yang merupakan elemen himpunan nilai derajat keanggotaan himpunan kabur yakni bilangan riil yang bernilai antara 0 sampai 1 .

Matriks kabur menggunakan operasi yang berbeda dengan matriks biasa. Operasi matriks kabur didefinisikan oleh Sidky \& Emam (1992) yaitu berupa operasi maksimum serta operasi minimum yang merupakan operasi yang sama seperti pada teori himpunan kabur. Lebih lanjut Pal (2016) dengan menggunakan definisi matriks kabur yang sama mengemukakan beberapa konsep operasi baru yang digunakan pada matriks kabur. Selain itu Pal (2016) mengemukakan beberapa definisi jenis khusus matriks kabur yang dibedakan berdasarkan nilai-nilai entri dari matriks kabur tersebut.

Kemudian berdasarkan konsep himpunan kabur dan operasinya tersebut penelitian ini mengemukakan teori perpaduan antara himpunan kabur dan aljabar, yakni matriks dan teori grup. Dalam penelitian ini dikemukakan teorema serta pembuktian untuk mengetahui karakteristik yang dimiliki himpunan matriks kabur persegi dengan operasi yang didefinisikan terhadap sifat-sifat 
aljabar untuk teori grup dan ring. Jadi garis besar hasil akhir dari penelitian ini akan menyimpulkan sifat-sifat aljabar yang dipenuhi oleh matriks kabur persegi dengan menggunakan operasi tertentu terhadap teori grup dan ring serta lebih mendalam pada semigrup dan semi ring.

\section{KAJIAN PUSTAKA}

\section{Matriks Kabur}

Teori matriks kabur pertama kali dikemukakan oleh Thomason (1977). Kemudian Pal (2016) mengemukakan definisi matriks kabur secara lebih jelas. Matriks kabur tersebut secara matematis didefinisikan sebagai berikut:

Definisi 1 Diberikan $A$ sebuah matriks kabur dengan ordo $n \times m$, maka $A$ dapat ditulis sebagai $A=\left[\left\langle a_{i j}, \mu_{a}\left(a_{i j}\right)\right\rangle\right]_{n \times m}$ dimana $\mu_{a}\left(a_{i j}\right)$ adalah nilai keanggotaan dari elemen $a_{i j}$ dalam $A$ serta $i=1,2,3, \ldots$ dan $j=1,2,3, \ldots$. Secara singkat dapat ditulis $A=\left[\mu_{A}\left(a_{i j}\right)\right]$.

Entri pada matriks kabur dioperasikan sesuai operasi yang telah didefinisikan oleh Sidky \& Emam (1992). Operasi pada entri matriks kabur adalah sebagai berikut

(Pal, 2016)

Definisi 2 Diberikan sebuah himpunan $A=\{x ; x \in \mathbb{R} \mid 0 \leq x \leq 1\}$. Untuk setiap $a, b \in A$ berlaku operasi:

$$
\begin{aligned}
a \vee b & =\max \{a, b\} \\
a \wedge b & =\min \{a, b\} \\
a \ominus b & = \begin{cases}a ; & a>b \\
0 ; & a \leq b\end{cases}
\end{aligned}
$$

(Sidky \& Emam, 1992)

Selanjutnya Pal (2016) mengemukakan beberapa jenis khusus dari matriks kabur. Diantaranya adalah sebagai berikut:

- Matriks kabur refleksif

- Matriks kabur irrefleksif

- Matriks kabur hampir irrefleksif

- Matriks kabur simetris

- Matriks kabur konstan

- Matriks kabur identitas

- Matriks kabur refleksif lemah

- Matriks kabur diagonal

\section{Teori Grup}

Grup merupakan salah satu kajian teori pada bidang matematika aljabar. Grup merupakan sebuah himpunan dengan sebarang operasi dan memenuhi syarat-syarat tertentu untuk dikatakan sebagai grup. Berikut ini definisi dari grup.

Definisi 3 Misalkan $G$ sebuah himpunan tidak kosong, terdapat operasi * pada $G,(G, *)$ disebut grup dengan operasi $*$ jika dan hanya jika memenuhi (Judson, 2013):

1. $(G, *)$ tertutup $\Leftrightarrow$ untuk setiap $a, b \in G$ berlaku $a * b \in G$

2. $(G, *)$ asosiatif $\Leftrightarrow$ untuk setiap $a, b, c \in G$ berlaku a $*(\mathrm{~b} * \mathrm{c})=(\mathrm{a} * \mathrm{~b}) * \mathrm{c}$

3. $(G, *)$ memiliki unsur identitas $\Leftrightarrow$ terdapat $e \in G$ sedemikian sehingga untuk setiap $a \in G$ berlaku $\mathrm{a} * \mathrm{e}=\mathrm{e} * \mathrm{a}=\mathrm{a}$ 
4. Setiap unsur dalam $(G, *)$ memiliki inversi. Untuk setiap $a \in G$ terdapat $a^{\prime}$ sehingga berlaku a $* \mathrm{a}^{\prime}=\mathrm{a}^{\prime} * \mathrm{a}=\mathrm{e}$, dimana $e$ merupakan unsur identitas $G$ dengan operasi *.

\section{METODE PENELITIAN}

Penelitian yang dilakukan merupakan jenis penelitian dasar atau matematika murni serta menggunakan metode studi literatur dengan membaca literatur-literatur yang berhubungan dengan matriks kabur dan operasi pada matriks kabur. Fokus kajian dalam penelitian ini terletak pada definisi matriks kabur, definisi operasi yang digunakan matriks kabur, serta teorema entri atau elemen matriks serta matriks kabur terhadap teori grup dan teori ring.

Tujuan yang terdapat dalam penelitian ini adalah untuk mengemukakan definisi matriks kabur, sebagai tahap paling awal dan sekaligus sebagai teori dasar untuk mendukung teori-teori yang dibahas stelahnya. Mengemukakan definisi operasi yang digunakan pada entri matriks kabur dan operasi yang digunakan pada matriks kabur. Mengemukakan definisi jenis-jenis khusus dari matriks kabur yang dikategorikan berdasarkan nilai entri-entrinya. Mengemukakan teorema teori grup dan teori ring terhadap matriks kabur persegi dan himpunan semua entri matriks kabur beserta dengan pembuktiannya.

\section{HASIL DAN PEMBAHASAN}

Seperti yang telah didefinisikan sebelumnya bahwa matriks kabur merupakan salah satu jenis matriks yang entri-entrinya berisi elemen nilai derajat keanggotaan himpunan kabur. Matriks kabur menggunakan operasi yang berbeda dengan matriks biasa, sebab jika menggunakan operasi biasa seperti pada matriks klasik, maka matriks kabur tidak akan bersifat tertutup.

Definisi operasi maksimum pada matriks kabur adalah sebagai berikut:

Definisi 4 Diberikan sebarang matriks kabur $A$ dan $B$, dimana

dan

$$
A=\left[\begin{array}{cccc}
a_{11} & a_{12} & \cdots & a_{1 m} \\
a_{21} & a_{22} & \cdots & a_{2 m} \\
\vdots & \vdots & \vdots & \vdots \\
a_{n 1} & a_{n 2} & \cdots & a_{n m}
\end{array}\right] ; \quad a_{i j} \in[0,1] ; i=1,2, \ldots, n j=1,2, \ldots, m
$$

$$
B=\left[\begin{array}{cccc}
b_{11} & b_{12} & \cdots & b_{1 m} \\
b_{21} & b_{22} & \cdots & b_{2 m} \\
\vdots & \vdots & \vdots & \vdots \\
b_{n 1} & b_{n 2} & \cdots & b_{n m}
\end{array}\right] ; \quad b_{i j} \in[0,1] ; i=1,2, \ldots, n j=1,2, \ldots, m
$$

Maka operasi $A \vee B$ adalah

$$
\begin{aligned}
A \vee B & =\left[\begin{array}{cccc}
a_{11} & a_{12} & \cdots & a_{1 m} \\
a_{21} & a_{22} & \cdots & a_{2 m} \\
\vdots & \vdots & \vdots & \vdots \\
a_{n 1} & a_{n 2} & \cdots & a_{n m}
\end{array}\right] \vee\left[\begin{array}{cccc}
b_{11} & b_{12} & \cdots & b_{1 m} \\
b_{21} & b_{22} & \cdots & b_{2 m} \\
\vdots & \vdots & \vdots & \vdots \\
b_{n 1} & b_{n 2} & \cdots & b_{n m}
\end{array}\right] \\
& =\left[\begin{array}{ccccc}
a_{11} \vee b_{11} & a_{12} \vee b_{12} & \cdots & a_{1 m} \vee b_{1 m} \\
a_{21} \vee b_{21} & a_{22} \vee b_{22} & \cdots & a_{2 m} \vee b_{2 m} \\
\vdots & \vdots & \vdots & \vdots \\
a_{n 1} \vee b_{n 1} & a_{n 2} \vee b_{n 2} & \cdots & a_{n m} \vee b_{n m}
\end{array}\right]
\end{aligned}
$$




$$
=\left[\begin{array}{cccc}
\max \left\{a_{11}, b_{11}\right\} & \max \left\{a_{12}, b_{12}\right\} & \cdots & \max \left\{a_{1 m}, b_{1 m}\right\} \\
\max \left\{a_{21}, b_{21}\right\} & \max \left\{a_{22}, b_{22}\right\} & \cdots & \max \left\{a_{2 m}, b_{2 m}\right\} \\
\vdots & \vdots & \vdots & \vdots \\
\max \left\{a_{n 1}, b_{n 1}\right\} & \max \left\{a_{n 2}, b_{n 2}\right\} & \cdots & \max \left\{a_{n m}, b_{n m}\right\}
\end{array}\right]
$$

(Pal, 2016)

Definisi operasi $\ominus$ pada matriks kabur adalah sebagai berikut:

Definisi 5 Diberikan sebarang matriks kabur $A$ dan $B$, dimana

$$
A=\left[\begin{array}{cccc}
a_{11} & a_{12} & \cdots & a_{1 m} \\
a_{21} & a_{22} & \cdots & a_{2 m} \\
\vdots & \vdots & \vdots & \vdots \\
a_{n 1} & a_{n 2} & \cdots & a_{n m}
\end{array}\right] ; a_{i j} \in[0,1] ; i=1,2, \ldots, n j=1,2, \ldots, m
$$

dan

$$
B=\left[\begin{array}{cccc}
b_{11} & b_{12} & \cdots & b_{1 m} \\
b_{21} & b_{22} & \cdots & b_{2 m} \\
\vdots & \vdots & \vdots & \vdots \\
b_{n 1} & b_{n 2} & \cdots & b_{n m}
\end{array}\right] ; \quad b_{i j} \in[0,1] ; i=1,2, \ldots, n j=1,2, \ldots, m
$$

Maka hasil operasi $A \ominus B$ adalah

$$
\begin{aligned}
A \ominus B & =\left[\begin{array}{cccc}
a_{11} & a_{12} & \cdots & a_{1 m} \\
a_{21} & a_{22} & \cdots & a_{2 m} \\
\vdots & \vdots & \vdots & \vdots \\
a_{n 1} & a_{n 2} & \cdots & a_{n m}
\end{array}\right] \ominus\left[\begin{array}{cccc}
b_{11} & b_{12} & \cdots & b_{1 m} \\
b_{21} & b_{22} & \cdots & b_{2 m} \\
\vdots & \vdots & \vdots & \vdots \\
b_{n 1} & b_{n 2} & \cdots & b_{n m}
\end{array}\right] \\
& =\left[\begin{array}{ccccc}
a_{11} \ominus b_{11} & a_{12} \ominus b_{12} & \cdots & a_{1 m} \ominus b_{1 m} \\
a_{21} \ominus b_{21} & a_{22} \ominus b_{22} & \cdots & a_{2 m} \ominus b_{2 m} \\
\vdots & \vdots & \vdots & \vdots \\
a_{n 1} \ominus b_{n 1} & a_{n 2} \ominus b_{n 2} & \cdots & a_{n m} \ominus b_{n m}
\end{array}\right]
\end{aligned}
$$

Dimana

$$
a_{i j} \ominus b_{i j}=\left\{\begin{array}{cc}
a_{i j} ; & a_{i j}>b_{i j} \\
0 ; & a_{i j} \leq b_{i j}
\end{array} ; a_{i j} \in A ; b_{i j} \in B\right.
$$

(Pal, 2016)

Operasi minimum pada matriks kabur didefinisikan sebagai berikut

Definisi 6 Diberikan sebarang matriks kabur $M$ dan $N$ dengan ordo masing-masing berturut-turut $p \times r$ dan $r \times q$ dimana

$$
\mathrm{M}=\left[\begin{array}{cccc}
\mathrm{m}_{11} & \mathrm{~m}_{12} & \cdots & \mathrm{m}_{1 \mathrm{r}} \\
\mathrm{m}_{21} & \mathrm{~m}_{22} & \cdots & \mathrm{m}_{2 \mathrm{r}} \\
\vdots & \vdots & \vdots & \vdots \\
\mathrm{m}_{\mathrm{p} 1} & \mathrm{~m}_{\mathrm{p} 2} & \cdots & \mathrm{m}_{\mathrm{pr}}
\end{array}\right] ; \mathrm{m}_{\mathrm{ij}} \in[0,1] \mathrm{i}, \mathrm{j} \in 1,2, \ldots
$$

Dan

$$
\mathrm{N}=\left[\begin{array}{cccc}
\mathrm{n}_{11} & \mathrm{n}_{12} & \cdots & \mathrm{n}_{1 \mathrm{q}} \\
\mathrm{n}_{21} & \mathrm{n}_{22} & \cdots & \mathrm{n}_{2 \mathrm{q}} \\
\vdots & \vdots & \vdots & \vdots \\
\mathrm{n}_{\mathrm{r} 1} & \mathrm{n}_{\mathrm{r} 2} & \cdots & \mathrm{n}_{\mathrm{rq}}
\end{array}\right] ; \quad \mathrm{n}_{\mathrm{ij}} \in[0,1] \mathrm{i}, \mathrm{j} \in 1,2, \ldots
$$

Maka hasil operasi $M \wedge N$ adalah 


$$
\begin{aligned}
M \wedge N & =\left[\begin{array}{ccc}
m_{11} n_{11} \vee m_{12} n_{21} \vee \ldots \vee m_{1 r} n_{r 1} & \cdots & m_{11} n_{1 q} \vee m_{12} n_{2 q} \vee \ldots \vee m_{1 r} n_{r q} \\
m_{21} n_{11} \vee m_{22} n_{21} \vee \ldots \vee m_{2 r} n_{r 1} & \cdots & m_{21} n_{1 q} \vee m_{22} n_{2 q} \vee \ldots \vee m_{2 r} n_{r q} \\
\vdots & \vdots & \vdots \\
m_{p 1} n_{11} \vee m_{p 2} n_{21} \vee \ldots \vee m_{p r} n_{r 1} & \cdots & m_{p 1} n_{1 q} \vee m_{p 2} n_{2 q} \vee \ldots \vee m_{p r} n_{r q}
\end{array}\right] \\
& =\left[\begin{array}{ccc}
m_{11} n_{11} \vee m_{12} n_{21} \vee \ldots \vee m_{1 r} n_{r 1} & \cdots & m_{11} n_{1 q} \vee m_{12} n_{2 q} \vee \ldots \vee m_{1 r} n_{r q} \\
m_{21} n_{11} \vee m_{22} n_{21} \vee \ldots \vee m_{2 r} n_{r 1} & \cdots & m_{21} n_{1 q} \vee m_{22} n_{2 q} \vee \ldots \vee m_{2 r} n_{r q} \\
\vdots & \vdots & \vdots \\
m_{p 1} n_{11} \vee m_{p 2} n_{21} \vee \ldots \vee m_{p r} n_{r 1} & \cdots & m_{p 1} n_{1 q} \vee m_{p 2} n_{2 q} \vee \ldots \vee m_{p r} n_{r q}
\end{array}\right]
\end{aligned}
$$

Dimana operasi $m_{i j} \wedge n_{i j}$ secara singkat dapat ditulis dengan $m_{i j} n_{i j}$. Operasi matriks di atas dapat dinyatakan dengan notasi berikut:

$$
\mathrm{M} \wedge \mathrm{N}=\left[\sum_{\mathrm{k}=1}^{\mathrm{r}} \mathrm{m}_{\mathrm{ik}} \wedge \mathrm{n}_{\mathrm{kj}}\right]
$$

Dimana operasi sigma adalah operasi maksimum dan operasi $m_{i k} \wedge n_{k j}$ adalah

$$
m_{i j} \wedge n_{i j}=m_{i j} n_{i j}=\min \left\{m_{i j}, n_{i j}\right\} ; m_{i j} \in M ; n_{i j} \in N
$$

(Pal, 2016)

Selanjutnya Pal (2016) mengemukakan beberapa operasi baru yang digunakan pada matriks kabur, pertama didefinisikan operasi untuk entri matriks kabur yang didefinisikan sebagai berikut:

Definisi 7 Diberikan $a, b$ elemen matriks kabur, untuk sebarang $a, b \in[0,1]$ berlaku:

$$
\begin{gathered}
a \oplus b=a+b-a \cdot b \\
a \odot b=a \cdot b
\end{gathered}
$$

(Pal, 2016)

Kemudian untuk setiap matriks kabur $A$ dan $B$ berlaku operasi yang didefinisikan sebagai berikut:

Definisi 8 Diberikan $A=\left[a_{i j}\right]$ dan $B=\left[b_{i j}\right]$ matriks kabur berordo $m \times n$, maka berlaku

$$
\begin{gathered}
A \oplus B=\left[a_{i j}+b_{i j}-a_{i j} \cdot b_{i j}\right] \\
A \odot B=\left[a_{i j} \cdot b_{i j}\right] \\
A^{[k+1]}=A^{[k]} \odot A ; A^{1}=A ; k=1,2, \ldots \\
{[k+1] A=[k] A \oplus A=1 A=A ; k=1,2, \ldots}
\end{gathered}
$$

(Pal, 2016)

Berdasarkan definisi operasi baru matriks kabur yang dikemukakan oleh Pal (2016), maka dalam penelitian ini dikemukakan teorema sebagai berikut:

Teorema 1 Diberikan $M$ suatu himpunan matriks kabur persegi, maka $M$ dengan operasi $\oplus$ merupakan grupoid.

Bukti Teorema 1 Ambil sebarang matriks kabur persegi $A, B \in M$ dimana $A=\left[a_{i j}\right]$ dan $B=$ $\left[b_{i j}\right]$ dengan $a_{i j}, b_{i j} \in[0,1]$. Akan dibuktikan $M$ tertutup dengan operasi $\bigoplus$.

$$
A \oplus B=\left[a_{i j} \oplus b_{i j}\right]=\left[a_{i j}+b_{i j}-a_{i j} b_{i j}\right]
$$

Akan ditunjukkan bahwa $a_{i j}+b_{i j}-a_{i j} b_{i j} \in[0,1]$. Perhatikan bahwa

1. Untuk $a_{i j}=0$ dan $b_{i j}=0$

$$
\begin{gathered}
a_{i j}+b_{i j}-a_{i j} b_{i j}=0+0-(0)(0) \\
=0-0 \\
=0 \in[0,1]
\end{gathered}
$$


2. Untuk $a_{i j}=1$ dan $b_{i j}=1$

$$
\begin{gathered}
a_{i j}+b_{i j}-a_{i j} b_{i j}=1+1-(1)(1) \\
=2-1 \\
=1 \in[0,1]
\end{gathered}
$$

3. Untuk $a_{i j}=0$ dan $b_{i j}=1$

$$
\begin{aligned}
a_{i j}+b_{i j}- & a_{i j} b_{i j}=0+1-0(1) \\
= & 0+1-0 \\
& =1 \in[0,1]
\end{aligned}
$$

4. Untuk $a_{i j}=1$ dan $b_{i j}=0$

$$
\begin{aligned}
a_{i j}+b_{i j}- & a_{i j} b_{i j}=1+0-1(0) \\
& =1+0-0 \\
& =1 \in[0,1]
\end{aligned}
$$

5. Untuk $a_{i j}$ dan $b_{i j}$ yang lain

Karena $a_{i j}, b_{i j} \in(0,1)$, maka berlaku pertidaksamaan $0<1-a_{i j}<1$ dan $0<1-$ $b_{i j}<1$. Akibatnya berlaku $0<\left(1-a_{i j}\right)\left(1-b_{i j}\right)<1$. Sehingga:

$$
\begin{gathered}
0<\left(1-a_{i j}\right)\left(1-b_{i j}\right)<1 \\
0<1-\left(a_{i j}+b_{i j}-a_{i j} b_{i j}\right)<1 \\
-1<-\left(a_{i j}+b_{i j}-a_{i j} b_{i j}\right)<0 \\
0<a_{i j}+b_{i j}-a_{i j} b_{i j}<1
\end{gathered}
$$

Dengan demikian terbukti bahwa $a_{i j}+b_{i j}-a_{i j} b_{i j} \in(0,1)$ sehingga $A \oplus B$ juga merupakan matriks kabur persegi. Jadi terbukti bahwa himpunan $M$ bersifat tertutup dengan operasi $\oplus$. Dengan demikian dapat dikatakan bahwa himpunan $M$ merupakan grupoid dengan operasi $\oplus$.

Teorema 2 Diberikan $M$ suatu himpunan matriks kabur persegi, maka $M$ dengan operasi $\oplus$ merupakan semigrup.

Bukti Teorema 2 Berdasarkan Teorema 1 bahwa $M$ merupakan grupoid, maka selanjutnya akan dibuktikan $M$ memenuhi sifat asosiatif.

Ambil sebarang matriks kabur persegi $A, B$, dan $C$ dimana $A=\left[a_{i j}\right], B=\left[b_{i j}\right]$, dan $C=\left[c_{i j}\right]$ dengan ukuran $n \times n$, dimana $a_{i j}, b_{i j}, c_{i j} \in[0,1]$ dan $i, j=1,2, \ldots, n$. Perhatikan bahwa

$$
\begin{aligned}
(A \oplus B) \oplus C & =\left(\left[a_{i j}\right] \oplus\left[b_{i j}\right]\right) \oplus\left[c_{i j}\right] \\
& =\left[a_{i j} \oplus b_{i j}\right] \oplus\left[c_{i j}\right] \\
& =\left[a_{i j}+b_{i j}-a_{i j} b_{i j}\right] \oplus\left[c_{i j}\right] \\
& =\left[\left(a_{i j}+b_{i j}-a_{i j} b_{i j}\right)+c_{i j}-\left(a_{i j}+b_{i j}-a_{i j} b_{i j}\right) c_{i j}\right] \\
& =\left[a_{i j}+b_{i j}+c_{i j}-a_{i j} b_{i j}-\left(a_{i j} c_{i j}+b_{i j} c_{i j}-a_{i j} b_{i j} c_{i j}\right)\right] \\
& =\left[a_{i j}+b_{i j}+c_{i j}-a_{i j} b_{i j}-a_{i j} c_{i j}-b_{i j} c_{i j}+a_{i j} b_{i j} c_{i j}\right] \\
& =\left[a_{i j}+b_{i j}+c_{i j}-b_{i j} c_{i j}-a_{i j} b_{i j}-a_{i j} c_{i j}+a_{i j} b_{i j} c_{i j}\right] \\
& =\left[a_{i j}+b_{i j}+c_{i j}-b_{i j} c_{i j}-\left(a_{i j} b_{i j}+a_{i j} c_{i j}-a_{i j} b_{i j} c_{i j}\right)\right] \\
& =\left[a_{i j}+\left(b_{i j}+c_{i j}-b_{i j} c_{i j}\right)-a_{i j}\left(b_{i j}+c_{i j}-b_{i j} c_{i j}\right)\right] \\
& =\left[a_{i j}\right] \oplus\left[b_{i j}+c_{i j}-b_{i j} c_{i j}\right] \\
& =\left[a_{i j}\right] \oplus\left[b_{i j} \oplus c_{i j}\right] \\
& =\left[a_{i j}\right] \oplus\left(\left[b_{i j}\right] \oplus\left[c_{i j}\right]\right)
\end{aligned}
$$




$$
=A \oplus(B \oplus C)
$$

Jadi terbukti bahwa himpunan $M$ memenuhi sifat asosiatif dengan operasi $\oplus$. Dengan demikian terbukti bahwa $M$ dengan operasi $\bigoplus$ merupakan semigrup.

Teorema 3 Diberikan $M$ suatu himpunan matriks kabur persegi, maka $M$ dengan operasi $\oplus$ merupakan monoid.

Bukti Teorema 3 Berdasarkan Teorema 2 bahwa $M$ merupakan semigrup, maka selanjutnya akan dibuktikan bahwa $M$ memiliki unsur identitas dengan operasi $\oplus$.

Ambil sebarang matriks kabur persegi $U=\left[u_{i j}\right]$ dimana untuk setiap $A=\left[a_{i j}\right]$ berlaku $u_{i j} \oplus$ $a_{i j}=a_{i j} \oplus u_{i j}=a_{i j}$. Perhatikan bahwa

$$
\begin{gathered}
a_{i j} \oplus u_{i j}=a_{i j} \\
a_{i j}+u_{i j}-a_{i j} u_{i j}=a_{i j} \\
a_{i j}+u_{i j}-a_{i j} u_{i j}-a_{i j}=a_{i j}-a_{i j} \\
u_{i j}-a_{i j} u_{i j}=0 \\
u_{i j}\left(1-a_{i j}\right)=0 \\
u_{i j}=\frac{0}{\left(1-a_{i j}\right)} \\
u_{i j}=0
\end{gathered}
$$

Ambil matriks kabur persegi $U=\left[u_{i j}\right]$ dimana $u_{i j}=0 \in[0,1]$. Sehingga untuk setiap $A=$ $\left[a_{i j}\right] \in M$ berlaku $A \oplus U=U \oplus A=A$. Perhatikan bahwa

$$
\begin{aligned}
A \oplus U & =\left[a_{i j}\right] \oplus\left[u_{i j}\right] \\
& =\left[a_{i j}+u_{i j}-a_{i j} u_{i j}\right] \\
& =\left[a_{i j}+0-a_{i j} 0\right] \\
& =\left[a_{i j}\right] \\
& =A \\
U \oplus A & =\left[u_{i j}\right] \oplus\left[a_{i j}\right] \\
& =\left[u_{i j}+a_{i j}-u_{i j} a_{i j}\right] \\
& =\left[0+a_{i j}-0 a_{i j}\right] \\
& =\left[a_{i j}\right] \\
& =A
\end{aligned}
$$

Dengan demikian terbukti bahwa terdapat suatu unsur identitas $U \in M$ dimana $U=\left[u_{i j}\right]$ dengan $u_{i j}=0 \in[0,1]$ sedemikian sehingga untuk setiap $A \in M$ berlaku $A \oplus U=U \oplus A=A$. Jadi berdasarkan uraian di atas, terbukti bahwa himpunan $M$ merupakan monoid dengan operasi $\oplus$

Berdasarkan teorema-teorema yang telah dikemukakan di atas, perhatikan bahwa suatu himpunan matriks kabur persegi merupakan monoid, namun suatu himpunan matriks kabur persegi bukan merupakan grup, karena terdapat suatu matriks kabur persegi yang tidak memiliki inversi dengan operasi $\oplus$. Hal tersebut dapat dilihat dari uraian berikut:

Diasumsikan terdapat $A^{\prime}=\left[a_{i j}^{\prime}\right]$ yang merupakan inversi dari sebarang matriks kabur persegi $A=\left[a_{i j}\right]$ sedemikian sehingga $A \oplus A^{\prime}=A^{\prime} \oplus A=U$ dimana $U=\left[u_{i j}\right]$ dengan $u_{i j}=0 \in$ $[0,1]$ berdasarkan pembuktian unsur identitas pada Teorema 3. Perhatikan bahwa

$$
\begin{gathered}
A \oplus A^{\prime}=U \\
{\left[a_{i j}+a_{i j}^{\prime}-a_{i j} a_{i j}^{\prime}\right]=\left[u_{i j}\right]}
\end{gathered}
$$




$$
\begin{gathered}
a_{i j}+a_{i j}^{\prime}-a_{i j} a_{i j}^{\prime}=0 \\
a_{i j}^{\prime}-a_{i j} a_{i j}^{\prime}=-a_{i j} \\
a_{i j}^{\prime}\left(1-a_{i j}\right)=-a_{i j} \\
a_{i j}^{\prime}=-\frac{a_{i j}}{1-a_{i j}}
\end{gathered}
$$

Perhatikan bahwa $-\left(\frac{a_{i j}}{1-a_{i j}}\right) \leq 0$ untuk setiap $a_{i j} \neq 1$. Dengan demikian nilai inversi dari suatu elemen matriks kabur persegi tidak bernilai positif atau dengan kata lain tidak berada dalam interval $[0,1]$. Jadi suatu himpunan matriks kabur persegi tidak dapat dikatakan sebagai grup.

\section{KESIMPULAN}

Kesimpulan yang diperoleh dari penelitian ini adalah sebagai berikut:

1. Matriks kabur memiliki beberapa jenis khusus diantaranya adalah matriks kabur refleksif, matriks kabur irrefleksif, matriks kabur hampir irrefleksif, matriks kabur simetris, matriks kabur konstan, matriks kabur identitas, matriks kabur refleksif lemah, dan matriks kabur diagonal.

2. Matriks kabur memiliki beberapa operasi, diantaranya adalah operasi maksimum, operasi minimum, operasi $\ominus$, operasi $\oplus$, dan operasi $\odot$.

3. Himpunan matriks kabur persegi merupakan monoid dengan operasi $\oplus$, atau dengan kata lain memenuhi sifat tertutup, sifat asosiatif, serta memiliki unsur identitas dengan operasi $\oplus$.

4. Himpunan matriks kabur persegi bukan merupakan grup sebab unsur identitasnya bernilai $-\left(\frac{a_{i j}}{1-a_{i j}}\right) \leq 0$ dan tidak terdapat pada interval tertutup $[0,1]$.

Melalui penelitian ini diharapkan dapat menjadi masukkan dalam meningkatkan wawasan serta pengetahuan khususnya dalam bidang aljabar tentang himpunan kabur dan matriks kabur. Selain itu penelitian ini merupakan penelitian matematika murni yang tentunya masih dapat dikembangkan lebih jauh dari apa yang telah disajikan dalam penelitian ini.

Pembahasan dalam penelitian ini sebagian besar hanya berfokus pada himpunan matriks kabur persegi serta operasi yang telah dikemukakan oleh peneliti terdahulu. Oleh karena itu, diharapkan kepada peneliti selanjutnya untuk mengkaji lebih dalam tentang teorema himpunan matriks kabur secara umum serta mengemukakan jenis operasi matriks kabur yang baru atau bahkan yang belum pernah dikemukakan oleh peneliti terdahulu.

\section{DAFTAR PUSTAKA}

Judson, T. W. (2013). Abstract Algebra; Theory and Applications. Texas: Free Software Foundation

Pal, M. (2016). Fuzzy Matrix and its Application. Fuzzy Matrices. 1-11.

Sidky, F., \& Emam, E. (1992). Some Remarks on Sections of a Fuzzy Matrix. J.K.A.U, 145-155.

Suroto, \& Wardayani, A. (2015). Semi Modul Interval [0,1] atas Semi Ring Matriks Fuzzy Persegi. Jurnal Jurusan Matematika Universitas Jenderal Soedirman. 79-84

Thomason, M. G. (1977). Convergence of Powers of a Fuzzy Matrix. Journal of Mathematical Analysis and Applications, 57. 476-480.

Zadeh, L. A. (1965). Fuzzy Sets. Information and Control, 8. 338-353. 